\title{
One day of work of the Teacher of Chemistry: narratives of college students about teaching activity
}

\section{Um dia de trabalho do professor de química: narrativas de licenciandos sobre a atividade docente}

\section{Un día de trabajo del profesor de química: narrativas de estudiantes universitarios sobre la actividad docente}

\author{
Rosana Franzen Leite $^{1}$ iD, Fabiele Cristiane Dias Broietti ${ }^{2}$ iD, Viviane Arrigo $^{2}$ iD \\ ${ }^{1}$ Universidade Estadual do Oeste do Paraná, Toledo, Paraná, Brasil. \\ 2 Universidade Estadual de Londrina, Londrina, Paraná, Brasil.
}

Autor correspondente:

Rosana Franzen Leite

Email: rosana.leite@unioeste.br

Como citar: Leite, R. F., Broietti, F. C. D., \& Arrigo, V. (2021). One day of work of the Teacher of Chemistry: narratives of college students about teaching activity. Revista Tempos e Espaços em Educação, 14(33), e14196.

http://dx.doi.org/10.20952/revtee.v14i33.14196

\begin{abstract}
The aim of this study was to investigate the process of teaching learning, priorities, desires and difficulties experienced by academics in Chemistry, when describing a day of class as a high school teacher. For this, on the first day of class of the Supervised Internship, of the Chemistry Degree course, academics were asked to produce a narrative text imagining what a working day as a Chemistry teacher would be like. This activity gave rise to 15 narratives, which were analyzed based on content analysis. Such an analytical procedure allowed the identification of two main categories, which were divided into subcategories. To discuss the results, the first category was selected: Image of a Chemistry teacher, which encompasses ideas about different methodologies, planning and time control, interpersonal relationships between teacher and student and between students, the profession as a job exhaustive and the teacher's clothes. In view of the results, it was possible to highlight multiple aspects as constituents of the teaching work, which highlights the need to expand the discussions held in the initial training courses, in addition to aspects related to disciplinary and didactic-pedagogical content.
\end{abstract}

Keywords: Chemistry. Initial formation. Narratives.

\section{RESUMO}

O objetivo deste estudo residiu em investigar o processo de aprendizagem da docência, prioridades, anseios e dificuldades vivenciadas por acadêmicos em Química, ao descreverem um dia de aula como professor do Ensino Médio. Para isso, no primeiro dia de aula da disciplina de Estágio 
Supervisionado, do curso de Licenciatura em Química, foi solicitado que os acadêmicos produzissem um texto narrativo imaginando como seria um dia de trabalho como professor de Química. Essa atividade deu origem a 15 narrativas, que foram analisadas com base na análise de conteúdo. Tal procedimento analítico permitiu a identificação de duas categorias principais, que se desdobraram em subcategorias. Para a discussão dos resultados foi selecionada a primeira categoria: Imagens do professor de Química, que abrange ideias acerca de metodologias diferenciadas, do planejamento e do controle do tempo, das relações interpessoais entre professor e aluno e entre os alunos, da profissão como um trabalho exaustivo e das vestimentas do professor. Diante dos resultados, foi possível destacar múltiplos aspectos como constituintes do trabalho docente, o que ressalta a necessidade de ampliar as discussões realizadas nos cursos de formação inicial, para além de aspectos relativos a conteúdos disciplinares e didático-pedagógicos.

Palavras-chave: Formação inicial. Narrativas. Química.

\section{RESUMEN}

El objetivo de este estudio fue investigar el proceso de enseñanza aprendizaje, las prioridades, los deseos y las dificultades experimentadas por los académicos en Química, al describir un día de clase como profesor de secundaria. Para esto, en el primer día de clase de la pasantía supervisada, del curso de Química, se pidió a los académicos que produjeran un texto narrativo que imaginara cómo sería un día de trabajo como profesor de Química. Esta actividad dio lugar a 15 narrativas, que fueron analizadas en base al análisis de contenido. Tal procedimiento analítico permitió la identificación de dos categorías principales, que se dividieron en subcategorías. Para analizar los resultados, se seleccionó la primera categoría: Imagen de un profesor de Química, que abarca ideas sobre diferentes metodologías, planificación y control del tiempo, relaciones interpersonales entre profesor y alumno y entre alumnos, la profesión como un trabajo exhaustivo y la ropa del profesor. En vista de los resultados, fue posible destacar múltiples aspectos como componentes del trabajo de enseñanza, lo que resalta la necesidad de ampliar las discusiones mantenidas en los cursos de capacitación iniciales, además de los aspectos relacionados con el contenido disciplinario y didáctico-pedagógico.

Palabras clave: Formación inicial. Narrativas. Química.

\section{INTRODUÇÃO}

A formação inicial de professores tem sido objeto de muitos estudos no campo do conhecimento profissional docente. Gatti (2014) aponta que o modelo de formação docente que se consolidou historicamente no país, desde as suas origens na década de 30 como adendo dos bacharelados, ainda oferece uma formação pedagógica superficial que não prepara os futuros professores para atuar nas escolas na contemporaneidade. Carvalho \& Gil-Pérez (2011) discutem que os professores de Ciências, quando são questionados sobre as destrezas e conhecimentos necessários para o exercício da profissão, em geral as respostas recaem sobre o conhecimento da matéria a ser ensinada e algumas habilidades didático-pedagógicas.

Percebe-se ainda uma visão reducionista acerca da atividade docente, na qual não se leva em consideração a singularidade, as incertezas e a complexidade do ambiente escolar, que exigem do professor conhecimentos que vão além do conhecimento dos conteúdos a serem ensinados. Nessa perspectiva Maldaner (2013) discute a respeito da pouca eficiência dos cursos de licenciatura no Brasil pelo fato de a maioria deles estarem pautados em um currículo de formação que separa a formação profissional específica da formação em conteúdos, estabelecendo uma sensação de vazio na mente do futuro professor. Afinal, de que adianta saber a Química e não saber transformá-la em conteúdo a ser ensinado? Tais apontamentos reforçam a visão de Gatti (2014) sobre a superficialidade com a qual os currículos das licenciaturas têm norteado tais cursos. 
Além disso, as críticas em torno da formação de professores vêm dos próprios estudantes quando começam a cursar as disciplinas de formação pedagógica, desaprovações essas que abrangem desde a falta de didática dos próprios professores do curso, até a dicotomia existente entre a teoria e a prática, o que demonstra uma insatisfação com o curso (Silva \& Schnetzler, 2008). Segundo Demo (2019) o acúmulo de versões pedagógicas modistas das licenciaturas revela uma formação embasada em uma prática dominante, de estilo instrucionista, sem fundamento teórico e prático e autonomia docente.

Tais discussões aparecem também nas Diretrizes para a Formação de Professores (Brasil, 2015), que discorrem sobre a necessidade de reformulação das matrizes curriculares dos cursos de licenciaturas e destacam como princípio formativo uma "efetiva e concomitante relação entre teoria e prática, ambas fornecendo elementos básicos para o desenvolvimento dos conhecimentos e habilidades necessários à docência" (Brasil, 2015, p. 30-31). De acordo com o referido documento, de um total de 3200 horas de curso, 800 horas são destinadas à formação prática e pedagógica, sendo 400 horas destinadas ao estágio supervisionado na área de formação e atuação na educação básica e 400 horas de atividades de práticas como componente curricular (Brasil, 2015).

Assim, entendemos que a matriz curricular desses cursos deve estar organizada de modo que permita uma formação na interface entre conhecimentos científicos e pedagógicos, de modo que a relação entre a teoria e a prática seja estabelecida em ambos os núcleos de conhecimento ao longo do curso e não somente durante a realização dos estágios supervisionados. Portanto, há a necessidade de repensar a formação inicial no sentido de oferecer aos futuros professores uma preparação que lhe confira autonomia no exercício da docência por meio da reflexão crítica dos aspectos práticos pedagógicos que permeiam a atividade docente. Nesse caso, compreendemos que o uso de narrativas na formação inicial de professores pode constituir-se como uma ferramenta para a reflexão, análise e (re)construção de ideias acerca da docência, com base nas teorias estudadas nas disciplinas e nas expectativas dos acadêmicos sobre a atividade docente.

Dessarte, relatamos nesta investigação algumas ideias de acadêmicos ${ }^{1}$ do curso de Licenciatura em Química de uma universidade pública do Paraná a respeito da atividade docente. Tais relatos advém de uma tarefa proposta durante a realização das atividades de estágio na disciplina de Estágio Supervisionado IV (Estágio de Regência), ofertada no 40 ano do curso. 0 objetivo do presente estudo foi investigar o processo de aprendizagem da docência, prioridades, anseios e dificuldades vivenciadas por acadêmicos em Química, ao descreverem um dia de aula como professor do Ensino Médio.

\section{CONSIDERAÇÕES SOBRE A FORMAÇÃO INICIAL DE PROFESSOES E O USO DE NARRATIVAS}

De acordo com as informações disponíveis na Sinopse Estatística da Educação Superior do ano de 2018, dados atuais viabilizados até o presente momento, mostram que foram efetivadas 8.450.755 matrículas em cursos de graduação presenciais e a distância, sendo apenas 1.628 .676 delas destinadas aos cursos de licenciatura. Um dado alarmante é a baixa procura pelos cursos de formação de professores de Ciências, principalmente das áreas de Física e Química, que contaram com um total de 28.732 e 37.881 matrículas, respectivamente (Inep, 2018).

Nessa perspectiva, Gatti (2016) aponta oito aspectos que interferem na qualidade dos cursos de formação de professores, a saber:

a) ausência de uma perspectiva de contexto social e cultural e do sentido social dos conhecimentos; b) a ausência nos cursos de licenciatura, e entre seus docentes formadores, de um perfil profissional claro de professor enquanto profissional (em muitos casos será preciso

\footnotetext{
1 Neste trabalho utilizamos o termo acadêmico para nos referirmos aos estudantes do curso de licenciatura, os licenciandos. Os dois termos serão utilizados como sinônimos. Optamos por estes termos para diferenciar do termo alunos, estudantes da Educação Básica, utilizado nas narrativas dos acadêmicos.
} 
criar, nos que atuam nesses cursos de formação, a consciência de que se está formando um professor; c) a falta de integração das áreas de conteúdo e das disciplinas pedagógicas dentro de cada área e entre si; d) a escolha de conteúdos curriculares; e) a formação dos formadores; f) a falta de uma carreira suficientemente atrativa e de condições de trabalho; g) ausência de módulo escolar com certa durabilidade em termos de professores e funcionários; h) precariedade quanto a insumos para o trabalho docente (Gatti, 2016, p. 168).

Tais dados e apontamentos indicam que o pouco interesse dos estudantes pelos cursos de licenciatura, principalmente da área de Química pode estar atrelado a baixa qualidade dos processos de formação, que acabam por leva-los a desistir do curso ou migrar para uma outra área. Isso reforça ainda mais a necessidade de reinventar a formação de professores no Brasil, buscando oferecer aos futuros docentes uma formação de qualidade, que os preparem para lidar com as demandas da disciplina, dos alunos e do ambiente escolar, contribuindo para a melhoria dos processos de ensino e de aprendizagem dos alunos nas escolas da Educação Básica.

Silva \& Oliveira (2009) apontam que o objetivo dos cursos de Licenciatura em Química é formar o professor para atuar na Educação Básica e que a formação de um bom professor deve contemplar: conhecimentos acerca do conteúdo a ser ensinado, do conhecimento curricular, conhecimento pedagógico sobre a disciplina escolar Química, conhecimentos sobre a construção do conhecimento científico, especificidades sobre o ensino e a aprendizagem da ciência Química, dentre outros. Nesse sentido, Shulman (1987) propõe uma Base de Conhecimentos de professores, constituída por sete conhecimentos, como vemos a seguir:

- Conhecimento do Conteúdo;

- Conhecimento Pedagógico Geral, com referência especial a amplos princípios e estratégias de gestão e organização da sala de aula que parecem transcender o assunto;

- Conhecimento do Currículo, com compreensão particular dos materiais e programas que servem como "ferramentas do ofício" para os professores;

- Conhecimento Pedagógico do Conteúdo (PCK), aquele amálgama especial entre conteúdo e pedagogia que é exclusivamente do domínio dos professores, sua própria forma de entendimento profissional;

- Conhecimento dos alunos e suas características;

- Conhecimento dos contextos educacionais, desde o funcionamento do grupo ou da sala de aula, a administração dos distritos escolares, até a caracterização das comunidades e culturas;

- Conhecimento dos fins, propósitos e valores educacionais e suas bases filosóficas e históricas ${ }^{2}$ (Shulman, 1987, p. 8, tradução nossa).

Concordamos que oferecer uma formação que congregue todos esses conhecimentos não é uma tarefa fácil para os professores-formadores e é nessa linha de pensamento que André (2010) discute as características das pesquisas norte-americanas sobre a formação de professores. Para a autora, essas pesquisas focalizam-se nas relações existentes entre características dos professores, formação e aprendizagem, sendo que, no Brasil, ainda é preciso incrementar as pesquisas para que essas articulem as concepções do professor, os processos de aprendizagem da docência e suas práticas de ensino.

\footnotetext{
2 Traduzido livremente a partir de: “-content knowledge; -general pedagogical knowledge, with special reference to those broad principles and strategies of classroom management and organization that appear to transcend subject matter; -curriculum knowledge, with particular grasp of the materials and programs that serve as "tools of the trade" for teachers; -pedagogical content knowledge, that special amalgam of content and pedagogy that is uniquely the province of teachers, their own special form of professional understanding; -knowledge of learners and their characteristics; -knowledge of educational contexts, ranging from the workings of the group or classroom, the governance and financing of school districts, to the character of communities and cultures; -knowledge of educational ends, purposes, and values, and their philosophical and historical grounds".
} 
Diante de tais aspectos e dessa preocupação com a formação docente, mais precisamente o desenvolvimento profissional do professor, como aponta Marcelo (2009), é necessário investigar como os acadêmicos estabelecem relações entre o que é discutido e destacado no curso de formação inicial e o que fariam na prática, ideias fundamentais para o desenvolvimento profissional dos futuros professores e para a melhoria dos processos de formação. Daí a necessidade de dar voz aos acadêmicos para expor as suas concepções, anseios, expectativas e experiências vivenciadas durante a graduação, sendo o uso das narrativas uma ferramenta potencial para favorecer o desenvolvimento profissional do futuro professor.

De acordo com Freitas \& Ghedin (2015), no Brasil, a utilização das narrativas de formação apareceu a partir dos anos de 1990 como prática de formação, investigação ou investigaçãoformação na área de Educação. Logo, a pesquisa narrativa pode contribuir tanto para a aprendizagem da docência quanto para a investigação de problemáticas envolvendo a formação de professores, tanto inicial quanto continuada. Marcelo (2009) afirma que a formação inicial de professores se caracteriza como uma etapa da formação profissional, ou seja, do desenvolvimento profissional do professor. O autor justifica o uso do termo "desenvolvimento", porque sugere evolução e continuidade, rompendo com o esquema tradicional de justaposição entre formação inicial e continuada.

Inúmeras maneiras poderiam ser utilizadas para a realização de um levantamento acerca das ideias dos acadêmicos, neste trabalho, optamos pelo uso das narrativas. De acordo com Galiazzi et al. (2008), a pesquisa narrativa tem sua utilização em diferentes campos do conhecimento, e por ela o mundo pode ser entendido e estudado, tendo a experiência das pessoas como ponto central, "pois o pensamento narrativo é uma forma fundamental de experiência e também uma forma de escrever e refletir sobre ela" (Galiazzi et al. 2008, p. 172). A autora ainda ressalta alguns aspectos importantes para a pesquisa narrativa, entre eles a temporalidade, evidenciando que uma experiência ocorre em determinado tempo e espaço, relacionando-se com o contexto em que o indivíduo vive.

As narrativas caracterizam um instrumento no qual são fornecidos alguns dos elementos que objetivamos destacar pela memória e imaginação dos atores envolvidos, deixando-os livres para escrever o texto e apresentar suas ideias (Freitas \& Galvão, 2007). É importante ressaltar que as situações descritas são sempre permeadas por relatos vivenciados pelo autor, imaginados por ele, ou ainda, por impressões de experiências vividas pelos outros (Gonçalves \& Fernandes, 2010). Além disso, compreendemos que quando se trata de um curso de Química, em que os alunos se debruçam no estudo de teorias, reações, fórmulas, equações, etc., o uso das narrativas pode contribuir para a inserção da escrita no contexto de formação, assim como o incentivo ao desenvolvimento da capacidade de análise, investigação e reflexão crítica, como relatam Utsumi et al. (2017) em uma pesquisa realizada na formação inicial de professores de Matemática.

Neste caso, visando o desenvolvimento profissional do professor entendemos que o uso das narrativas de formação em cursos de Licenciatura em Química podem constituir-se como uma ferramenta para que os acadêmicos exponham as suas concepções a respeito da docência, de como transformar conteúdos químicos em conteúdos a serem ensinados, com base nas teorias estudadas durante a graduação e nas experiências de ensino vivenciadas durante o curso, levando em consideração inúmeros aspectos que permeiam a atividade docente, como as características das escolas, dos alunos, da disciplina, dos materiais didáticos, dentre outros. Esse movimento de expor, refletir e analisar pode contribuir para a (re)construção de ideias acerca da docência, favorecendo a aprendizagem da docência dos futuros professores.

\section{CONTEXTO DA PESQUISA E METODOLOGIA DA INVESTIGAÇÃO}

A presente investigação foi realizada na disciplina de Prática de Ensino de Química e Estágio Supervisionado IV, do curso de Licenciatura em Química de uma universidade pública do Paraná. A 
referida disciplina, de caráter anual, é ofertada no 40 ano do curso e para cursá-la é necessário ter concluído as disciplinas anteriores de práticas de ensino e estágio de observação, assim os sujeitos desta pesquisa, os acadêmicos em Química, já estavam um pouco familiarizados com discussões acerca das tendências e pesquisas da área de ensino de química, bem como tinham vivenciado algumas experiências nas escolas durante o estágio de observação.

O Estágio de Observação, disciplina ofertada no 30 ano do curso propicia ao futuro professor, conhecimentos básicos relativos às condições em que se realizam o trabalho e a gestão na Educação Básica. Também possibilita o estudo de referenciais teóricos pertinentes à área, para que o acadêmico possa estar preparado para analisar criticamente o ambiente escolar (Broietti \& Stanzani, 2016). Na disciplina de Estágio de Regência, ofertada no 40 ano do curso, os acadêmicos elaboram e desenvolvem sequências de aulas experimentais e teóricas para alunos do Ensino Médio, além de outras atividades relacionadas à docência. Nessa disciplina os acadêmicos participam de reuniões quinzenais na universidade e ainda desenvolvem suas atividades na escola, paralelamente (Broietti \& Stanzani, 2016).

Nesse contexto, e considerando que ao chegar à reta final do curso, os acadêmicos apresentam algumas ideias sobre a docência, propusemo-nos realizar esta investigação, de caráter qualitativo, que está pautada na interpretação de situações e falas dos atores sociais envolvidos, os acadêmicos em Química (Alves-Mazzotti \& Gewandsznajder, 2004). Para isso, tomamos como base o artigo desenvolvido por Gonçalves et al. (2005), no qual os autores (professores-pesquisadores) realizaram em parceria com professores da Educação Básica uma investigação com alunos do Ensino Médio sobre a docência em Química e o docente dessa disciplina.

A visão dos alunos foi explicitada através de uma produção textual, chamada narrativa, em que cada aluno elaborou uma história se colocando no papel de professor de Química. A partir de um texto que narrava a história do menino chamado João, de 15 anos de idade, que entrou em uma máquina do tempo deixada no quintal e passou por uma transformação, os alunos deveriam imaginar que também tivessem entrado nessa máquina e viajado por alguns anos. Então, de forma semelhante ao que havia ocorrido com João, os alunos tinham que narrar uma história, com riqueza de detalhes, sobre essa nova vida, no papel de professor de Química, imaginando como seria um dia de trabalho nesta profissão.

Em nossa investigação, solicitamos no primeiro dia de aula da disciplina de Estágio de Supervisionado que os acadêmicos produzissem narrativas com base em suas ideias acerca da docência e do professor de Química, construídas até o presente momento do curso, da mesma forma como foi realizado na pesquisa de Gonçalves et al. (2005), descrevendo um dia de trabalho na profissão de professor de Química de uma escola da rede pública. Optamos pela escola pública por ser ela, inicialmente, nossa responsabilidade como universidade pública, e também, por ser na escola pública que as políticas educacionais são inseridas. Enquanto a escola particular pode trabalhar com inúmeros detalhes considerados sobressalentes, a escola pública deve cumprir o mínimo exigido por lei.

As narrativas caracterizam um instrumento no qual são fornecidos alguns dos elementos que objetivamos destacar pela memória e imaginação dos atores envolvidos, deixando-os livres para escrever o texto (Freitas \& Galvão, 2007). Optamos por esse instrumento por concordarmos com Gonçalves \& Fernandes (2010) em relação ao objetivo maior das narrativas: não apenas coletar dados, mas também potencializar a escrita desses acadêmicos. Deste procedimento foram obtidas 15 narrativas, as quais foram analisadas de acordo com os pressupostos da Análise de Conteúdo descritos por Bardin (2011).

Como já mencionado, a turma investigada era composta por 15 acadêmicos, sendo oito mulheres e sete homens na faixa etária de 20 a 30 anos de idade. Desses, apenas três possuíam pouca experiência na docência, pois atuavam há menos de um ano como professor PSS - Processo Seletivo Simplificado - na rede pública de ensino do estado do Paraná, Brasil. Outra informação é 
que $88,24 \%$ dos acadêmicos apresentavam a licenciatura como habilitação de ingresso, sendo que $11,76 \%$ ingressaram no bacharelado e, naquele momento, cursavam a licenciatura concomitantemente. Os acadêmicos podem, a partir do segundo ano, cursar outras habilitações em concomitância. Eles acabam fazendo essa opção por diversos motivos: cursar disciplinas no contra turno, ter mais oportunidades no campo profissional depois de formados, ou ainda durante a formação.

A seguir apresentamos o processo de análise e interpretação dos resultados obtidos.

\section{ANÁLISE E DISCUSSÃO DOS RESULTADOS}

A análise de conteúdo realizada nos textos produzidos, revisitando o referencial estudado, nos permitiu estabelecer categorias e subcategorias, que discutimos na sequência. Na tabela 1 apresentamos um resumo com as categorias e subcategorias encontradas.

Tabela 1. Categorias e subcategorias identificadas nas narrativas.

CATEGORIAS

1. Imagens do professor de Química

2. Ambiente escolar
SUBCATEGORIAS

a) Metodologias diferenciadas

b) Planejamento e controle do tempo

c) Relações interpessoais

d) Trabalho exaustivo

e) Vestimentas

a) O comportamento dos estudantes

b) $O$ espaço físico e a rotina

De posse das narrativas destacamos duas grandes categorias recorrentes nas descrições dos licenciandos: 1) Imagens do professor de Química e 2) Ambiente escolar. No que diz respeito à primeira categoria, discutimos fragmentos que remetem a algumas subcategorias, como as metodologias de ensino selecionadas pelo professor; destaque à necessidade de planejamento e controle do tempo da aula; a importância das relações interpessoais, principalmente no que se refere às relações entre professor-aluno e aluno-aluno; à docência como um trabalho exaustivo; e uma ênfase às vestimentas do professor de química. Nessa categoria que trata das Imagens do professor de Química do Ensino Médio é possível destacar a ideia de Marcelo (2009) no que se refere à identidade profissional: o autor a considera um elemento inseparável do desenvolvimento profissional e menciona tanto os vários fatores que a influenciam (como a escola, as reformas e contextos políticos) como suas implicações, ou seja:

[...] o compromisso pessoal, a disponibilidade para aprender a ensinar, as crenças, os valores, o conhecimento sobre as matérias que ensinam e como as ensinam, as experiências passadas, assim como a própria vulnerabilidade profissional (Marcelo, 2009, p. 7).

Com relação à segunda categoria - Ambiente escolar - as narrativas apontam para elementos que se referem ao comportamento dos alunos, o espaço físico da escola e a sua rotina. O ambiente vivenciado na escola caracteriza um dos conflitos mencionados por Bejarano \& Carvalho (2003). Nesse conflito os estagiários sempre esperam algo da escola, mas, na sua prática, os insucessos acontecem e são relacionados a esses fatores característicos do ambiente escolar, tais como a participação ou não dos estudantes frente à proposta de estudo do professor. Isso, para os estagiários, remete ao comportamento dos estudantes, sua disposição em estudar, enfim, um conflito relacionado ao currículo e à instrução, mas que passa pelas relações estabelecidas em sala de aula. 
Neste trabalho optamos por apresentar e discutir apenas a primeira categoria - Imagens do professor de Química -, suas subcategorias e unidades de análise, que seguem sistematizadas na tabela 2. Na sequência, trazemos para discussão, alguns fragmentos dos textos escritos pelos acadêmicos que caracterizam as subcategorias originadas da análise.

Tabela 2. Categorização das narrativas dos acadêmicos - As imagens do professor.

\begin{tabular}{|c|c|c|c|}
\hline CATEGORIA & SUBCATEGORIAS & UNIDADES DE ANÁLISE & TOTAL \\
\hline \multirow{5}{*}{$\begin{array}{l}\text { 1. Imagens do professor de } \\
\text { Química }\end{array}$} & a) Metodologias diferenciadas & $\begin{array}{l}\text { A01; A02; A03; A04; A05; A07; A08; A10; } \\
\text { A11; A12; A14 }\end{array}$ & 11 \\
\hline & $\begin{array}{l}\text { b) Planejamento e controle do } \\
\text { tempo }\end{array}$ & A04; A07; A09; A13; A15 & 5 \\
\hline & c) Relações interpessoais & A07; A08; A10; A12 & 4 \\
\hline & d) Trabalho exaustivo & $\mathrm{A} 11 ; \mathrm{A} 13 ; \mathrm{A} 15$ & 3 \\
\hline & e) Vestimentas & A03; A05; A10 & 3 \\
\hline
\end{tabular}

Para representar os acadêmicos utilizamos o código " $A$ " e as narrativas por eles produzidas foram numeradas de 01 a 15. Sendo assim, A04, significa que o excerto pertence à narrativa do acadêmico de número 4.

A seguir explicamos em detalhe cada uma dessas subcategorias.

\section{Metodologias diferenciadas}

Nesta subcategoria agrupamos os trechos nos quais se destacam a preocupação dos licenciandos com o uso de uma metodologia diferente da habitual, detectada nos excertos a seguir: “[...] Radioatividade, é esse o assunto de hoje. Tenho pouca experiência, mas já aprendi que traçar outro caminho e se livrar um pouco do quadro, giz e livro é um ótimo remédio para a cara feia e hoje o dia é de filme, um filme sobre radioatividade" (A01).

"Decidi que a aquela aula seria diferente pois, era evidente que qualquer que fosse minha metodologia utilizada até o presente momento não havia agradado muito aquela turma de $3^{\circ}$ ano do ensino médio [...]" (A02).

“[...] trabalhei com a leitura e discussão de um texto, pois o meu objetivo era fazer uma contextualização do conteúdo. Trabalhei depois com um vídeo, pois a minha intenção era ministrar uma aula dinâmica e prender a atenção dos alunos. Por fim desenvolvi com a turma um experimento [...]" (A11).

Na narrativa de A01, o licenciando descreve sua preocupação em empregar estratégias de ensino que façam com que os alunos se interessem pelo conteúdo a ser abordado. Ele busca resolver o problema passando um filme sobre o assunto a ser estudado. Destaca também a importância em variar um pouco a metodologia. No relato de $\mathrm{A} 02$, o acadêmico deixa explícito que as suas aulas poucas vezes agradavam a turma, e que, naquela aula específica, utilizaria outra metodologia. Ao longo da narrativa, A02 expõe "[...] pensava que ensinar era sinônimo de passar muito conteúdo, [...], portanto, decidi começar a aula conversando com os alunos sobre a química, [...] valorizando o conhecimento prévio dos alunos". Já na narrativa de A11 aparecem diversos recursos sendo utilizados: leitura de textos; vídeo e atividade experimental. $\mathrm{O}$ acadêmico também menciona a necessidade de contextualizar o conteúdo como uma forma de tornar a aula mais atrativa e interessante para os estudantes. 
Pensar e propor diferentes metodologias advém do conhecimento sobre como ensinar determinado conteúdo, conhecimento esse que se refere à compreensão docente do que facilita ou dificulta o aprendizado de um conteúdo específico, bem como as concepções errôneas dos estudantes e suas implicações na aprendizagem (Shulman, 1987; Almeida \& Biajone, 2007). É comum nos depararmos com ideias que defendem, por exemplo, que ensinar consiste apenas em transmitir conhecimentos - bastando, portanto, conhecer o conteúdo - que é uma questão de talento, bom senso, intuição ou, ainda, que basta ter experiência e cultura (Almeida \& Biajone, 2007).

Se compreendermos a atividade docente conforme apresentado por Carvalho \& Gil-Pérez (2011), este conhecimento de "conteúdo" implicaria em vários outros aspectos, tais como, compreender aspectos da construção desse conhecimento, bem como os obstáculos epistemológicos envolvidos; as relações entre Ciência, Tecnologia e Sociedade a ele relacionadas; a seleção dos conteúdos; as orientações metodológicas, enfim, não se tratando apenas do recorte conceitual. Nesse sentido, a preocupação desses acadêmicos em fazer uso de metodologias diversificadas revela uma preocupação com o processo de ensino e aprendizagem, que indica a construção de um perfil docente pautado não só no que ensinar e sim no que e como ensinar para gerar aprendizagem nos alunos. Tais ideias, aliadas aos apontamentos dos autores acima citados, reforçam a importância de ações formativas para além do conhecimento do conteúdo a ser ensinado, para uma formação na interface entre os conhecimentos específicos e os pedagógicos.

\section{Planejamento e controle do tempo}

Os acadêmicos mencionam duas atitudes do professor como fundamental: o controle do tempo para as tarefas propostas e o planejamento das aulas. Entretanto, talvez o foco nesse aspecto possa ser considerado um problema, uma vez que o tempo, da maneira como foi destacado, é um determinante do trabalho do professor, quando, na verdade, não deveria ser. De acordo com os relatos presentes nas narrativas, os acadêmicos limitam suas atividades em função do tempo, e não em função do objetivo didático, como vemos nos excertos a seguir:

\footnotetext{
"Após uns 20 minutinhos de conversa com os alunos (tempo este que só foi disponibilizado por tratar-se do primeiro dia de aula do ano, é claro) [...]" (A04).

"Como não poderia faltar estava com o meu planejamento da aula decorado na cabeça prossegui a aula apresentando o cronograma da disciplina [...]" (A07).

"O sinal toca vou para a primeira aula, turma do primeiro ano, começo a passar uma aula teórica (previamente montada no dia anterior), sobre ligação química, uso o datashow, passo conteúdo no quadro, resolvemos juntos alguns exercícios, dou outros, para resolverem sozinhos, no final, proponho um trabalho e faço a chamada, passo para a próxima aula" (A13).
}

No texto de A04, o acadêmico deixa evidente que só "perdeu" esse tempo por se tratar do primeiro dia de aula, destacando que é preciso manter certo ritmo ao longo da aula. Ao final do relato de $A 13$, o licenciando também menciona as etapas executadas na aula: apresentação do conteúdo, resolução de exercícios, tarefa de casa e chamada, evidenciando que o professor deve ter claro o controle do tempo da aula e os passos a serem seguidos.

Com relação ao planejamento, tanto A07 quanto A13 ressaltam que ministram uma aula cujo planejamento foi executado anteriormente e que, dessa forma, sentem-se seguros em ministrá-las. Trata-se, infelizmente, de certo apego ao conteúdo, ao currículo da escola e a necessidade de ter um roteiro a ser seguido, que acaba se sobressaindo aos próprios objetivos de ensino, fundamentais no planejamento de uma aula. Um professor muito preocupado com o tempo 
desprendido a cada etapa do seu trabalho pode deixar de abordar questões importantes e de utilizar metodologias de ensino mais complexas, limitando sua aula a aspectos mais clássico, inclusive negligenciando questionamentos interessantes dos alunos que podem surgir ao longo da aula.

Abreu (2010) discute que a valorização do conhecimento químico passa pelo contexto social, ambiental e tecnológico, e que isso acontece de forma sistematizada com o conteúdo específico, o que demanda tempo. Ao mencionarem o tempo como fator determinante do trabalho docente, os acadêmicos nos revelam uma preocupação distorcida do trabalho em sala de aula. O tempo é de fato importante, mas o destaque dado por eles nos leva a crer que os demais fatores não são levados em consideração nas proporções que realmente merecem.

\section{Relações interpessoais}

O ambiente de trabalho e as relações que o professor estabelece com os colegas e com seus estudantes também são mencionados, revelando-nos a importância atribuída a esse aspecto, como vemos a seguir:

"[...] quando entrei na sala cumprimentei a todos com um bom dia bem entusiasmado, visto que a turma estava muito agitada. Me apresentei e pedi que todos se apresentassem e que falassem um pouco de si para promover uma maior interação aluno-aluno e aluno-professor" (A07).

"[...] encontrei meus alunos que ao me verem me cumprimentavam como um sinal de amizade e de respeito, pois era com essa cumplicidade que chegamos as mais variadas discussões [...]. Chegando na escola encontro meus colegas de trabalho os professores onde posso conversar e apresentar ideias que possam trazer conteúdos e temas para que haja interdisciplinaridade" (A08).

Para o acadêmico A07 a interação aluno-aluno e aluno-professor são de grande importância para o bom andamento da aula, fato esse também destacado pelo acadêmico A08, uma vez que ressalta que, ao cumprimentar seus alunos, externaliza sinal de amizade e respeito e que essa cumplicidade auxilia, inclusive, nas discussões em sala de aula. Outro ponto mencionado por esse acadêmico é sua relação com os colegas de trabalho, relação essa que conta com troca de experiências e desenvolvimento de projetos conjuntos.

Nesse contexto, concordamos com Paro (2001) ao afirmar que:

[...] sendo a escola o local em que se realiza educação sistematizada precisa ser o ambiente mais propício possível à prática da democracia. Por isso, na realização da educação escolar a coerência entre os meios e fins exige que tanto a estrutura didática quanto a organização do trabalho no interior da escola estejam dispostas de modo a favorecer relações democráticas (Paro, 2001, p. 52).

Nas narrativas apresentadas pelos licenciandos notamos considerável destaque nessas relações, que podem favorecer tanto a criação de um ambiente de respeito e troca de experiências em todo o ambiente escolar, como um ambiente propício para a aprendizagem, quando nos referimos as relações estabelecidas em sala de aula. Essas relações podem contribuir significativamente para a construção de um discurso reflexivo por parte do professor durante as aulas, que fornece espaço para discussões, exposições de ideias e apontamentos que caminham no sentido da construção de novos conhecimentos por parte dos alunos. 


\section{Trabalho exaustivo}

Nesta subcategoria o foco está no trabalho exaustivo do professor, divulgado pela mídia e pelos professores que estão na ativa, principalmente com relação ao trabalho no contra turno. Seguem alguns fragmentos das narrativas analisadas:

\footnotetext{
"Na parte da tarde trabalho elaborando as próximas aulas, projetos e aulas práticas [...]" (A13).

"Ao final dos 100 minutos transcorridos, afinal eram duas aulas seguidas, eu já estava exausto, mas o dia só estava começando ainda teria mais 3 aulas em duas turmas diferentes. [...] Ao chegar em casa ainda fiquei acordado até meia noite planejando o conteúdo das aulas a serem ministradas de acordo com cada turma [...]" (A15).
}

No primeiro fragmento notamos o destaque dado pelo acadêmico ao mencionar que no contra turno (período da tarde) prepara suas aulas, desenvolve projetos e roteiros para atividades práticas. Já o licenciando A15 destaca o cansaço em dar as cinco aulas do período e que, além disso, fica acordado até tarde preparando as aulas do dia seguinte.

Os aspectos apontados pelos licenciandos revelam o que alguns autores (Zaragoza, 1999; Jesus, 1998) denominam de mal-estar docente, caracterizando-o por comportamentos que expressam insatisfação profissional, elevado nível de estresse, falta de empenho em relação à profissão e desejo de abandonar a carreira profissional. Para esses autores os motivos que levam a esse mal-estar são diversos e vão desde as mudanças ocorridas na sociedade, como a democratização do ensino, os avanços tecnológicos, as mudanças na estrutura familiar até a saída da mulher para o mercado de trabalho, pois muitas das funções educativas acabaram sendo transferidas para a escola, acarretando uma responsabilidade maior ao professor.

Nessa perspectiva, as questões de horário e trabalho fora da escola possuem mérito significativo, principalmente no que tange à valorização da profissão do professor. Contudo, talvez essa imagem de professor sobrecarregado e possuidor de um legado baseado na vocação acabe por atrapalhar a formação de novos professores, pois impede que a profissão docente se fortaleça, com base em formação adequada e contínua. Isso ainda enfraquece as lutas pela melhoria dessas condições de trabalho, uma vez que já se consolidam como características dessa profissão, confirmando-se uma visão comum e popular de professor.

\section{Vestimentas}

Nesta subcategoria estão agrupadas as ideias que revelam um estereótipo de professor de Química muito semelhante ao estereótipo de químico/cientista, conforme se pode observar nos seguintes relatos:

\footnotetext{
"[...] Eu estava de guarda-pó e algumas pessoas vestidas iguais a mim me cumprimentavam [...]" (A03)

"Ao sair de casa levei comigo alguns livros e um guarda-pó branco" (A05)

"Vestia adequadamente o guarda-pó, usava os óculos de proteção e os meus sapatos eram de couro, preto e bem fechados" (A10).
}

Na narrativa de A03 e A05, os licenciandos mencionam o uso do guarda-pó como uma vestimenta que caracteriza um tipo específico de profissional, talvez seja o jaleco de químico, talvez o jaleco de professor daquela escola. A05 acrescenta a essa caracterização os livros que, junto à vestimenta, compõem o perfil desse profissional. O estudante A10, além do guarda-pó, destaca o uso de óculos de proteção e sapatos de couro e fechados, detalhando a vestimenta que deve ser utilizada, principalmente, em uma aula de laboratório. 
É interessante notar que, no trabalho de Gonçalves et. al. (2005), os estudantes do ensino médio também destacam algumas dessas mesmas características, tais como as vestimentas do profissional da Ciência - o guarda-pó branco - fruto provavelmente de uma imagem estereotipada do cientista, advinda, principalmente, da mídia, segundo os mesmos autores. Se os acadêmicos mencionaram tal vestimenta com o mesmo significado que os estudantes do Ensino Médio essa semelhança se mostra - para nós - um tanto preocupante, pois na fase em que se encontram os acadêmicos estes já deveriam ter noções mais abrangentes do que é ser cientista e trabalhar com a ciência, já que estão no último ano da graduação.

De fato, é importante refletir sobre isso, pois, ao mencionarem "jaleco, óculos e sapatos fechados" parece uma tendência mais relacionada ao químico de laboratório, que precisa utilizar os EPIs - Equipamentos de Proteção Individual - por segurança. Entretanto, também nos indica uma forte influência da formação "endurecida" que alguns desses acadêmicos ainda tiveram, já que destacam esses itens como tão importantes quanto os livros do professor, por exemplo.

Sanmartí (2002) menciona que professores das áreas de ciências possuem ideias deturpadas da ciência e do cientista, e isso influencia sobremaneira na atuação desse professor ao ensinar essa ciência. Sem ter noções básicas sobre o trabalho científico e as situações problemáticas nas quais o conhecimento fora construído, fica difícil, para o professor, criar situações em sala que envolvam os mesmos problemas e as mesmas questões.

\section{EM VIAS DE CONCLUSÃO...}

Com relação à primeira categoria - Imagens do professor de Química - (que discutimos mais detalhadamente) os acadêmicos destacam a necessidade do uso de metodologias diferenciadas, a importância do planejamento e do controle do tempo, as relações interpessoais no ambiente escolar, seja entre os alunos, os professores ou professor e aluno, o trabalho do professor como sendo exaustivo, pois, além de ministrarem suas aulas, precisam se dedicar, no contra turno, à preparação de aulas do dia seguinte, desenvolvimento de projetos, entre outras atividades. Há também os que destacaram as vestimentas desse tipo de profissional.

Já a segunda categoria - Ambiente escolar - (apresentada na análise somente em linhas gerais) engloba o comportamento dos estudantes, o espaço físico e a rotina da escola. Com relação ao comportamento, mencionam barulho, indisciplina, falta de interesse, alunos sonolentos e até mesmo aqueles que se destacam por sua atenção e respeito nas aulas ministradas. Quanto ao espaço físico e à rotina do trabalho docente, os licenciandos detalham elementos que compõem a sala de aula, a sala dos professores e o laboratório de ciências, além da prática habitual em acordar cedo, ir à escola, ministrar as aulas e retornar para casa.

Investigar as ideias, atitudes desses acadêmicos frente a uma sala de aula, atuando como professor de Química no Ensino Médio é, segundo Bejarano \& Carvalho (2003, p. 2), "uma promissora rota de pesquisa na medida em que crenças influenciam percepções e julgamentos das pessoas". Para esses autores, o desenvolvimento profissional do professor está relacionado ao desenvolvimento das crenças desse professor, enfim, àquilo que ele acredita sobre si e sobre o seu papel de professor.

O espaço de trabalho do professor já é ponto de investigação e prática (especialmente no estágio supervisionado) nos trabalhos de Carvalho (2012), nos quais se observa de maneira direcionada esse ambiente e suas nuances, mas torna-se ainda mais enriquecedor a partir das narrativas de licenciandos. Também cabe mencionar que ainda há ausência de reconhecimento do papel de professor de Química como educador, ou educador químico, que, segundo Maldaner (2008):

Em uma visão ampliada, educadores químicos são sujeitos sociais ou pessoas que lidam com as coisas da Química e, com base em conhecimentos específicos, transacionam significados para 
as coisas da química com outras pessoas com as quais interagem: características de produtos químicos, cuidados ambientais, cuidados pessoais, reconhecimento dos materiais do ponto de vista de suas propriedades, usos, produção e armazenamento. As pessoas que, de alguma forma, dominam algum campo desse saber interagem socialmente e, com isso, criam atos de significação que constituem outras pessoas (Maldaner, 2008, p. 271).

Segundo Francisco Jr. et al. (2009, p. 113), o educador químico "configura-se, basicamente, por possuir conhecimentos no âmbito da Química e no âmbito da Educação, perfazendo uma conexão necessária entre essas duas esferas de conhecimento". Contudo, há certa ausência desse educador químico no Brasil, o que enfraquece a Educação Química nos cursos de licenciatura, e não possibilita o elo necessário entre Química e Educação, sobretudo nos componentes pedagógicos como Didática, Metodologia do Ensino de Química, Instrumentação para o Ensino de Química, Estágio Supervisionado, entre outras (Maldaner, 2008; Francisco Jr. et al, 2009).

Poucos desses aspectos são mencionados nos textos produzidos. Talvez falte ainda aos licenciandos reconhecerem-se como educadores químicos, cabendo à formação inicial proporcionar tal reflexão. É preciso que, em nossas disciplinas de estágio e prática de ensino, o acadêmico, futuro professor, possa refletir não simplesmente sobre os conceitos químicos e estratégias de ensino, mas, principalmente, sobre o contexto escolar, sua função social como integrante daquele contexto, sobre a escola como sistema inserido em um sistema maior.

\section{CONSIDERAÇÕES FINAIS}

Diante do objetivo deste estudo, investigar o processo de aprendizagem da docência, prioridades, anseios e dificuldades vivenciadas por acadêmicos em Química, ao descreverem um dia de aula como professor do Ensino Médio, constatamos algumas ideias externalizadas pelos acadêmicos que se desdobraram a partir de dois pontos principais, que representam as categorias que emergiram do procedimento analítico adotado: imagens do professor de Química e o ambiente escolar.

Assim, orientamos nossa reflexão para tecer essas considerações a partir da caracterização profissional desses acadêmicos, para um desenvolvimento profissional docente embasado na reflexão crítica acerca da docência, dos limites e das possibilidades que o professor pode se deparar nessa profissão. Destacamos que a formação inicial, mesmo com todos os entraves que já conhecemos, é a etapa mais propícia para tal caracterização. Nossa sugestão é de que os cursos de formação inicial promovam, não apenas no estágio supervisionado, mas em todas as disciplinas componentes do currículo, inclusive as de conhecimentos específicos, discussões acerca da profissão docente, do ser professor de Química.

Dessa forma, a imagem de professor de Química será melhor construída, para além daquela que somente o estágio (e todas as suas tensões) possibilitam. Acreditamos, assim como Silva \& Oliveira (2009), que a formação do professor é um processo contínuo e que não se inicia, e muito menos se finda, em um curso de graduação, nesse sentido, é preciso proporcionar ações formativas necessárias e fundamentais para a prática futura do docente.

Contribuições dos Autores: Leite, R. F.: concepção e desenho, aquisição de dados, análise e interpretação dos dados, redação do artigo, revisão crítica relevante do conteúdo intelectual; Broietti, F. C. D.: concepção e desenho, aquisição de dados, análise e interpretação dos dados, redação do artigo, revisão crítica relevante do conteúdo intelectual; Arrigo, V.: concepção e desenho, aquisição de dados, análise e interpretação dos dados, redação do artigo, revisão crítica relevante do conteúdo intelectual. Todas as autoras leram e aprovaram a versão final do manuscrito.

Aprovação Ética: Não aplicável.

Agradecimentos: Não aplicável. 


\section{REFERÊNCIAS}

Abreu, R. G. (2010). Comunidade disciplinar de ensino de química na produção de políticas curriculares para o ensino médio no Brasil. (Tese de Doutorado). Universidade Federal do Rio de Janeiro, Rio de Janeiro.

Almeida, P. C. A., \& Biajone, J. (2007). Saberes docentes e formação inicial de professores: implicações e desafios para as propostas de formação. Educação e Pesquisa, 33(2), 281-295. https://doi.org/10.1590/S1517-97022007000200007

Alves-Mazzotti, A. J., \& Gewandsznajder, F. (2004). O Método nas Ciências Naturais e Sociais: pesquisa Quantitativa e Qualitativa. 2 ed. São Paulo: Thomson.

André, M. (2010). Formação de professores: a constituição de um campo de estudos. Educação, 33(3), $174-181$. https://revistaseletronicas.pucrs.br/ojs/index.php/faced/article/view/8075

Broietti, F. C. D., \& Stanzani, E. L. (2016). Os estágios e a formação inicial de professores: experiências e reflexões no curso de Licenciatura em Química da UEL. Química Nova na Escola, 38(3), 306-317. https://doi.org/10.21577/0104$\underline{8899.20160042}$

Bardin, L. (2011). Análise de Conteúdo. São Paulo: Edições 70.

Bejarano, N. R. R., \& Carvalho, A. M. P. (2003). Tornando-se professor de ciências: crenças e conceitos. Ciência \& Educação, 9(1) 1-15. https://doi.org/10.1590/s1516-73132003000100001

Brasil (2015). Diretrizes Curriculares Nacionais para a formação inicial em nível superior (cursos de licenciatura, cursos de formação pedagógica para graduados e cursos de segunda licenciatura) e para a formação continuada. Diário Oficial [da] República Federativa do Brasil, 1(124), 8-12. http://portal.mec.gov.br/docman/agosto-2017-pdf/70431res-cne-cp-002-03072015-pdf/file

Carvalho, A. M. P. (2012). Os estágios nos cursos de licenciatura. São Paulo: Cengage Learning.

Carvalho, A. M. P., \& Gil-Pérez, D. (2011). Formação de professores de ciências: tendências e inovações. 10. ed. São Paulo: Cortez.

Demo, P. (2019). Discutindo a preparação de professores. In: Imbernón, F., Shigunov Neto, A. \& Fortunato, I. (Orgs.). Formação permanente de professores: experiências iberoamericanas. São Paulo: Edições Hipótese, p. 51-64.

Francisco Junior, W. E., Peternele, W. S., \& Yamashita, M. (2009). A formação de professores de Química no estado de Rondônia: necessidades e apontamentos. Química Nova na Escola, 31(2), 113-122.

http://qnesc.sbq.org.br/online/qnesc31 2/09-PEQ-9408.pdf

Freitas, D., \& Galvão, C. (2007). O uso das narrativas autobiográficas no desenvolvimento profissional de professores. Ciências e Cognição, 12, 219-233. http://www.cienciasecognicao.org/revista/index.php/cec/article/view/648

Freitas, L. M., \& Ghedin, E. L. (2015). Narrativas de formação: origens, significados e usos na pesquisa-formação de professores. Revista Contemporânea de Educação, 10(19), 111.131. https://doi.org/10.20500/rce.v10i19.1929

Galiazzi, M. C., Viveiro, A., Zanon, Â. M., Morales, A. G. M., Abreu, D. G., Sim, E. F. C., Silveira, F. P. R. A., Silva, M. V., Fonseca, N. A., \& Marchiorato, S. M. (2008). Narrar histórias para se constituir educador ambiental pela pesquisa. Pesquisa em Educação Ambiental, 3(1), 171-185. https://doi.org/10.18675/2177-580X.vol3.n1.p171-185

Gatti, B. A. (2014). A formação inicial de professores para a educação básica: as licenciaturas. Revista USP, (100), 3346. https://doi.org/10.11606/issn.2316-9036.v0i100p33-46

Gatti, B. A. (2016). Formação de professores: condições e problemas atuais. Revista Internacional de Formação de Professores (RIFP), 1(2), 161-171. https://periodicos.itp.ifsp.edu.br/index.php/RIFP/article/view/347/360

Gonçalves, F. P., \& Fernandes, C. S. (2010). Narrativas Acerca da Prática de Ensino de Química: Um Diálogo na Formação Inicial de Professores. Química Nova na Escola, 32(2) 120-127.

http://webeduc.mec.gov.br/portaldoprofessor/quimica/sbq/QNEsc32 2/10-PE-2309.pdf

Gonçalves, F. P., Lindemann, R., Galiazzi, M. C., \& Souza, M. (2005). Como é ser professor de química: histórias que nos revelam. In: IV Encontro Ibero-Americano de coletivos escolares e redes de professores que fazem investigação na sua escola. http://ensino.univates.br/ 4iberoamericano/trabalhos/trabalho086.pdf

Inep. (2019). Sinopse Estatística da Educação Superior 2018. Brasília: Inep, 2019. Disponível em:

http://inep.gov.br/web/guest/sinopses-estatisticas-da-educacao-superior

Jesus, S. N. (1998). Bem-estar dos professores: estratégias para realização e desenvolvimento profissional. Portugal: Porto Editora. 
Maldaner, O. A. (2008). A pós-graduação e a formação do educador químico. In: Rosa, M. I. P., Rossi, A. V. (Orgs). Educação Química no Brasil: Memórias, Política e Tendências. Campinas: Átomo, p. 269-288.

Maldaner, O. A. (2013). A formação inicial e continuada de professores de química: professor/pesquisador. 4 ed. ljuí: Editora Unijuí.

Marcelo, C. (2009). Desenvolvimento Profissional: passado e futuro. Sísifo: Revista de Ciências da Educação, (8), 7-22. http://sisifo.ie.ulisboa.pt/index.php/sisifo/article/view/130

Paro, V. H. (2001). Escritos sobre educação. São Paulo: Xamã.

Sanmartí, N. (2002). Didáctica de las ciencias en la educación secundaria obligatoria. Madrid: Sintesis Educación.

Shulman, L. (1987). Knowledge and teaching: foundations of the new reform. Harvard Educational Review, 57(1), 1-21. https://doi.org/10.17763/haer.57.1.j463w79r56455411

Silva, C. S., \& Oliveira, L. A. A. (2009). Formação inicial de professores de química: formação específica e pedagógica. In: Nardi, R (Org.) Ensino de ciências e matemática I: temas sobre formação de professores. São Paulo: Editora UNESP, p. 43-57.

Silva, R. M. G., \& Schnetzler, R. P. (2008). Concepções e ações de formadores de professores de química sobre o estágio supervisionado: propostas brasileiras e portuguesas. Química Nova, 31(8), 2174-2183.

https://doi.org/10.1590/S0100-40422008000800045

Utsumi, M. C., Zuffi, E. M., \& Rodrigues, E. A. P. (2017). O uso de narrativas na formação inicial de professores de Matemática. Jornal Internacional de Estudos em Educação Matemática, 10(3), 154-

163. https://doi.org/10.17921/2176-5634.2017v10n3p154-163

Recebido: 6 de agosto de 2020 | Aceito: 24 de julho de 2021 | Publicado: 21 de agosto de 2021

This is an Open Access article distributed under the terms of the Creative Commons Attribution License, which permits unrestricted use, distribution, and reproduction in any medium, provided the original work is properly cited. 